\title{
Genomic prediction of lactation curves for milk, fat, protein, and somatic cell score in Holstein cattle
}

\author{
H. R. Oliveira, ${ }^{1,2 *}$ L. F. Brito, ${ }^{1}$ F. F. Silva, ${ }^{2}$ D. A. L. Lourenco, ${ }^{3}$ J. Jamrozik, ${ }^{1,4}$ and F. S. Schenkel ${ }^{1}$ \\ ${ }^{1}$ Centre for Genetic Improvement of Livestock, Department of Animal Biosciences, University of Guelph, Guelph, Ontario, Canada, N1G2W1 \\ ${ }^{2}$ Department of Animal Science, Universidade Federal de Viçosa, Viçosa, Minas Gerais, Brazil, 36570-000 \\ ${ }^{3}$ Department of Animal and Dairy Science, University of Georgia, Athens 30602 \\ ${ }^{4}$ Canadian Dairy Network, Guelph, Ontario, Canada, N1K1E5
}

\section{ABSTRACT}

Application of random regression models (RRM) in a 2-step genomic prediction might be a feasible way to select young animals based on the complete pattern of the lactation curve. In this context, the prediction reliability and bias of genomic estimated breeding value (GEBV) for milk, fat, and protein yields and somatic cell score over days in milk (DIM) using a 2-step genomic approach were investigated. In addition, the effect of including cows in the training and validation populations was investigated. Estimated breeding values for each DIM (from 5 to $305 \mathrm{~d}$ ) from the first 3 lactations of Holstein animals were deregressed and used as pseudophenotypes in the second step. Individual additive genomic random regression coefficients for each trait were predicted using RRM and genomic best linear unbiased prediction and further used to derive GEBV for each DIM. Theoretical reliabilities of GEBV obtained by the RRM were slightly higher than theoretical reliabilities obtained by the accumulated yield up to 305 d (P305). However, validation reliabilities estimated for GEBV using P305 were higher than for GEBV using RRM. For all traits, higher theoretical and validation reliabilities were estimated when incorporating genomic information. Less biased GEBV estimates were found when using RRM compared with P305, and different validation reliability and bias patterns for GEBV over time were observed across traits and lactations. Including cows in the training population increased the theoretical reliabilities and bias of GEBV; nonetheless, the inclusion of cows in the validation population does not seem to affect the regression coefficients and the theoretical reliabilities. In summary, the use of RRM in 2-step genomic prediction produced fairly accurate GEBV over the entire lactation curve for all analyzed

Received June 4, 2018.

Accepted September 16, 2018.

*Corresponding author: holivier@uoguelph.ca traits. Thus, selecting young animals based on the pattern of lactation curves seems to be a feasible alternative in genomic selection of Holstein cattle for milk production traits.

Key words: days in milk, genomic breeding value, longitudinal trait, random regression model

\section{INTRODUCTION}

Genome-wide selection (GWS) is a landmark for modern livestock breeding programs because it has the potential to increase the reliability of breeding values, especially for selection of candidates at a young age, enabling a reduction in the generation interval and, consequently, increasing the genetic gain per unit of time. Additionally, GWS reduces the costs associated with progeny testing schemes that have been used in dairy cattle for a long time (Schaeffer, 2006).

There are several economically important traits in dairy cattle, such as milk production and composition traits, which are defined as longitudinal traits. Nowadays, the majority of genomic studies have focused on accumulated yield up to $305 \mathrm{~d}$ (P305) as the phenotype to predict genomic breeding values (Winkelman et al., 2015; Aliloo et al., 2016; Jenko et al., 2017). However, previous studies have reported advantages of using random regression models (RRM) over the P305 models to analyze longitudinal traits (Schaeffer et al., 2000; Jensen, 2001). Briefly, P305 models are not able to account for genetic variation in production over time and consequently do not allow for selection of animals based on the complete pattern of the production curve.

The selection of animals based on the complete lactation curves would take into account the lactation biology and the physiological implications of different curve patterns. In a practical way, this may help decrease the energy deficiency experienced during early and peak lactation and therefore can improve health, welfare, and fertility traits. In addition, RRM are also more advantageous compared with P305 because selec- 
tion can be efficiently performed based on points of interest throughout the lactation curve. To overcome the limitations of P305 models, some studies have used the predicted P305 from traditional BLUP random regression genetic evaluation as a phenotype for 2-step GWS (Ding et al., 2013; Brown et al., 2016). The steps involved in the 2-step GWS approach are (1) estimation of breeding value based on traditional evaluation and its deregression and (2) estimation of direct genomic value (DGV) using deregressed EBV from step 1 as a phenotype for the genomic BLUP (GBLUP); subsequently, DGV can be combined with parent average (PA) into genomic EBV (GEBV). However, this strategy of only using RRM in the first-step genetic evaluation still does not allow making inferences over time because only the total GEBV is predicted in the second step.

To predict GEBV over time, recent studies have used RRM in single-step genomic evaluations (Koivula et al., 2015; Jattawa et al., 2016; Baba et al., 2017). However, the single-step GBLUP method (Misztal et al., 2009; Aguilar et al., 2010; Christensen and Lund, 2010 ) is not currently used for official genomic evaluations in several countries, including Canada (Interbull, 2017). Thus, the application of RRM in both steps of a 2-step GWS could provide a suitable alternative to select genotyped animals based on the pattern of the lactation curve. Therefore, the main goals of this study were to (1) investigate the reliability and bias of GEBV over DIM, in a 2-step approach, for milk, fat, and protein yields and SCS in the first 3 lactations of Holstein cattle; (2) compare the prediction reliability and bias of GEBV from RRM with the prediction reliability and bias of GEBV from the P305 model; and (3) compare the prediction reliability and bias of GEBV obtained from RRM and from the P305 model with the prediction reliability and bias of PA. In addition, the effect of incorporating cows in the training and validation populations was investigated.

\section{MATERIALS AND METHODS}

No Animal Care Committee approval was necessary for the purposes of this study, as all information required was obtained from existing databases.

\section{Data Sets}

The Canadian Dairy Network (CDN; Guelph, ON, Canada) provided the pedigree, genotypes, and EBV for the individual genetic regression coefficients and reliabilities from December 2012 and December 2016 genetic evaluation runs. The EBV for the individual ge- netic regression coefficients were available for milk, fat, and protein yields and SCS from the first 3 lactations of Holstein cattle. The only available reliabilities for each trait and animal were the average reliabilities over the first 3 lactations for the accumulated yields. The total number of animals in the official genetic evaluation in the 2012 and 2016 runs was 4,888,808 and 5,683,640, respectively. Traits were coded as MY1, FY1, PY1, SCS1, MY2, FY2, PY2, SCS2, MY3, FY3, PY3, and SCS3, where MY, FY, and PY are milk, fat, and protein yields, respectively, and 1,2, and 3 refer to the first, second, and third lactations, respectively.

Phenotypes. The EBV for each lactation day were derived using the EBV for genetic regression coefficients predicted by CDN based on 2 multiple-trait random regression test-day animal models (Schaeffer et al., 2000), one considering milk, fat, and protein yields in the first 3 lactations and the other considering SCS in the first 3 lactations, as routinely performed by CDN. Details about the RRM used by CDN are fully presented in Interbull (2018a,b). In brief, both models included the fixed effects of herd-test day-parity and DIM (from 5 to $305 \mathrm{~d}$ ), fixed regression curves for yearseason-region-parity-age of calving effect, and random regression curves for herd-year of calving and additive genetic and permanent environment effects. Fixed and random regressions were modeled by fourth-order Legendre orthogonal polynomials, and heterogeneity of residual variance was taken into account by fitting 10 classes of residual variances in each parity. The pattern of the average EBV over DIM for each trait is shown in Supplemental Figure S1 (https://doi.org/10.3168/jds .2018-15159).

The EBV from 5 to 305 DIM were used in the analyses. For all animals used in the second step of GWS (i.e., the genotyped animals), the PA and the theoretical reliability of PA were estimated as shown in VanRaden and Wiggans (1991) using the parent information available in the 2012 evaluation. To perform the analysis considering the traditional P305 model in the second step of GWS, accumulated EBV and PA of each animal were obtained by summing up the EBV and PA of each day for each trait. Because a single theoretical reliability per animal for each trait was available from CDN, reliabilities of the EBV for all DIM and for P305 were assumed to be the same.

To avoid double-counting of information and double shrinkage of the DGV by using EBV as pseudophenotypes, EBV are usually deregressed before their use in genomic evaluations (Garrick et al., 2009; Oliveira et al., 2018). Therefore, deregressed daily and accumulated EBV (dEBV) were used as pseudophenotypes for each animal in the genomic evaluation of all traits. 
Because using well-established methods of deregression for nonlongitudinal traits is a feasible alternative for obtaining dEBV used in the genomic prediction of longitudinal traits (Oliveira et al., 2018), $\mathrm{dEBV}_{i}$ of animal $i$ for each day and for the P305 were computed according to VanRaden et al. (2009):

$$
\mathrm{dEBV}_{i}=\mathrm{PA}_{i}+\frac{\left(\mathrm{EBV}_{i}-\mathrm{PA}_{i}\right)}{\mathrm{R}_{i}},
$$

where $\mathrm{PA}_{i}$ is the $\mathrm{PA}$ for animal $i, \mathrm{EBV}_{i}$ is the $\mathrm{EBV}$ for animal $i$, and $\mathrm{R}_{i}$ is the deregression factor computed as follows:

$$
\mathrm{R}_{i}=\frac{\mathrm{ERC}_{(\mathrm{Ind}-\mathrm{PA})_{i}}}{\mathrm{ERC}_{(\mathrm{Ind}-\mathrm{PA})_{i}}+\mathrm{ERC}_{\mathrm{PA}_{i}}+1},
$$

where the effective record contributions (ERC) for animal $i$ excluding the PA information $\left[\mathrm{ERC}_{(\operatorname{Ind}-\mathrm{PA})_{i}}\right]$ and the ERC for the PA $\left(\mathrm{ERC}_{\mathrm{PA}_{i}}\right)$ of animal $i$ were estimated based on VanRaden and Wiggans (1991) and Přibyl et al. (2013):

$$
\mathrm{ERC}_{(\mathrm{Ind}-\mathrm{PA})_{i}}=\left(\lambda \frac{\mathrm{REL}_{\mathrm{EBV}_{i}}}{1-\mathrm{REL}_{\mathrm{EBV}_{i}}}\right)-\mathrm{ERC}_{\mathrm{PA}_{i}}
$$

and

$$
\mathrm{ERC}_{\mathrm{PA}_{i}}=\lambda \frac{\mathrm{REL}_{\mathrm{PA}_{i}}}{1-\mathrm{REL}_{\mathrm{PA}_{i}}},
$$

in which $\lambda=\left(1-\mathrm{h}^{2}\right) / \mathrm{h}^{2}$, and $\mathrm{REL}_{\mathrm{EBV}_{i}}$ and $\mathrm{REL}_{\mathrm{PA}_{i}}$ are the theoretical reliabilities for EBV and PA of animal $i$, respectively. Average heritabilities $\left(\mathrm{h}^{2}\right)$ along the lactation curves considered for MY1, FY1, PY1, SCS1, MY2, FY2, PY2, SCS2, MY3, FY3, PY3, and SCS3 were estimated by $\mathrm{CDN}$ as $0.31,0.27,0.27,0.14,0.29$, $0.26,0.27,0.18,0.26,0.24,0.24$, and 0.21 , respectively (Interbull, 2018a,b). To avoid double-counting of information due to the fact that an animal without its own phenotype or without phenotypes of its daughters would have their own EBV calculated solely based on $\mathrm{PA}$, animals that did not have their own performance or progeny information $\left[\mathrm{ERC}_{(\text {Ind-PA })_{i}}=0\right]$ were excluded from the analyses.

Genotypes. Only animals with genotypic information were included in the second step of the GWS analysis. Animals were genotyped or accurately imputed to the Illumina BovineSNP50K BeadChip (Illumina, San Diego, CA). FImpute software (Sargolzaei et al., 2011) was used for imputation. Details about the accuracy of imputation for Canadian breeds can be found in Larmer et al. (2014).

After the genotype imputation process performed by CDN, SNP with Mendelian conflicts, a call rate less than 0.95 , a minor allele frequency less than 0.01 , and a difference between observed and expected heterozygosity frequency higher than 0.15 (Wiggans et al., 2009) were removed using preGSF90 software version 1.10 (Aguilar et al., 2014). A total of 43,556 SNP distributed over the 29 bovine autosomes remained in the data set after the quality control.

\section{Statistical Analysis}

Training and Validation Populations. Genomic predictions were performed for each trait separately. Genotyped animals included in the official Canadian evaluation performed in the 2012 genetic evaluation run were used as a training population; genotyped animals born after 2012, which were present in the 2016 genetic evaluation run, were used as a validation population. In addition, bulls born from 2007 to 2010 that only had daughters born after 2012 were included in the validation population.

To investigate the effect of inclusion of cows in the training and validation populations, 3 scenarios were evaluated: (1) considering only bulls in the training and validation populations, (2) considering bulls and cows in the training population and only bulls in the validation population, and (3) considering bulls and cows in the training and validation populations. Based on preliminary analysis (results not shown), it was required that animals (bulls and cows) included in the training population had a minimum reliability of EBV of 0.65 for each trait. In addition, it was required that bulls and cows included in the validation population have a minimum reliability of EBV of 0.80 and 0.65 for each trait, respectively. A detailed description of all training and validation populations is shown in Table 1 .

GBLUP P305. Accumulated DGV for each animal were predicted using the accumulated dEBV as pseudophenotypes based on the GBLUP method (VanRaden, 2008). The traditional single-trait animal model used for P305 is described as follows:

$$
\mathbf{y}_{\mathrm{ac}}=\mathbf{1} \mu+\mathbf{W}_{\mathrm{ac}} \mathbf{g}_{\mathrm{ac}}+\mathbf{e}_{\mathrm{ac}},
$$

where $\mathbf{y}_{\mathrm{ac}}$ is the vector of pseudophenotypic accumulated records, $\mu$ is the overall mean, $\mathbf{W}_{\mathrm{ac}}$ is the incidence matrix relating the random animal genomic effects $\left(\mathrm{g}_{\mathrm{ac}}\right)$ to P305, and $\mathbf{e}_{\mathrm{ac}}$ is the vector of residuals for P305. The model assumptions were 


$$
\mathrm{E}\left[\mathbf{y}_{a c}\right]=\mu
$$

and

$$
\operatorname{Var}\left[\begin{array}{l}
\mathbf{g}_{a c} \\
\mathbf{e}_{a c}
\end{array}\right]=\left[\begin{array}{cc}
\mathbf{G} \sigma_{g_{a c}}^{2} & 0 \\
0 & \mathbf{I} \sigma_{e_{a c}^{2}}^{2}
\end{array}\right],
$$

where $\sigma_{g_{a c}}^{2}$ and $\sigma_{e_{a c}}^{2}$ are the genomic and residual variances for P305, and $\mathbf{I}$ is the identity matrix. $\mathbf{G}$ is the genomic relationship matrix, which was created as in VanRaden (2008):

$$
\mathbf{G}=0.95 \frac{\mathbf{Z Z}^{\prime}}{2 \sum_{k=1}^{K} p_{k}\left(1-p_{k}\right)}+0.05 \mathbf{A},
$$

where $\mathbf{Z}=\mathbf{M}-\mathbf{P}$, in which $\mathbf{M}$ contains the centered genotypes (i.e., $-1,0$, and 1 to represent $\mathrm{AA}, \mathrm{Aa}$, and aa, respectively) and $\mathbf{P}$ contains allele frequency for SNP $k\left(p_{k}\right)$ in its $k$ th column, expressed as $2\left(p_{k}-0.5\right)$; $2 \sum_{k=1}^{K} p_{k}\left(1-p_{k}\right)$ is a scaling parameter; and $\mathbf{A}$ is the traditional (pedigree-based) additive relationship matrix, which included a total of 39,918 animals. To guarantee that $\mathbf{G}$ matrix was positive definite, $5 \%$ of $\mathbf{A}$ was added to $95 \%$ of $\mathbf{G}$ (VanRaden, 2008).

GBLUP RRM. Genomic random regression coefficients for each animal were also predicted using the GBLUP method (VanRaden, 2008). In matrix notation, the RRM used for each trait was

$$
\mathbf{y}=\mathbf{X b}+\mathbf{W g}+\mathbf{e}
$$

where $\mathbf{y}$ is the vector of pseudophenotypic records (dEBV for each DIM); $\mathbf{X}$ and $\mathbf{W}$ are the incidence matrices for the vectors of fixed regression coefficients (b) and genomic random regression coefficients (g), which were modeled by fourth-order Legendre orthogonal polynomials (Kirkpatrick et al., 1990); and e is the vector of residuals. The model assumptions were

$$
\mathrm{E}[\mathbf{y}]=\mathbf{X b}
$$

and

$$
\operatorname{Var}\left[\begin{array}{l}
\mathbf{g} \\
\mathbf{e}
\end{array}\right]=\left[\begin{array}{cc}
\mathbf{G}_{0} \otimes \mathbf{G} & 0 \\
0 & \sigma_{e}^{2} \otimes \mathbf{I}
\end{array}\right],
$$

where $\mathbf{G}_{0}$ is the variance-covariance matrix of the genomic random regression coefficients, $\sigma_{e}^{2}$ is the residual

Table 1. Total number of animals and bulls, years of birth ${ }^{1}$ (YOB), and mean (SD) of effective record contributions (ERC) and reliability of estimated breeding values $\left(\mathrm{REL}_{\mathrm{EBV}}\right)$ for the training and validation populations used in the genomic prediction of each trait

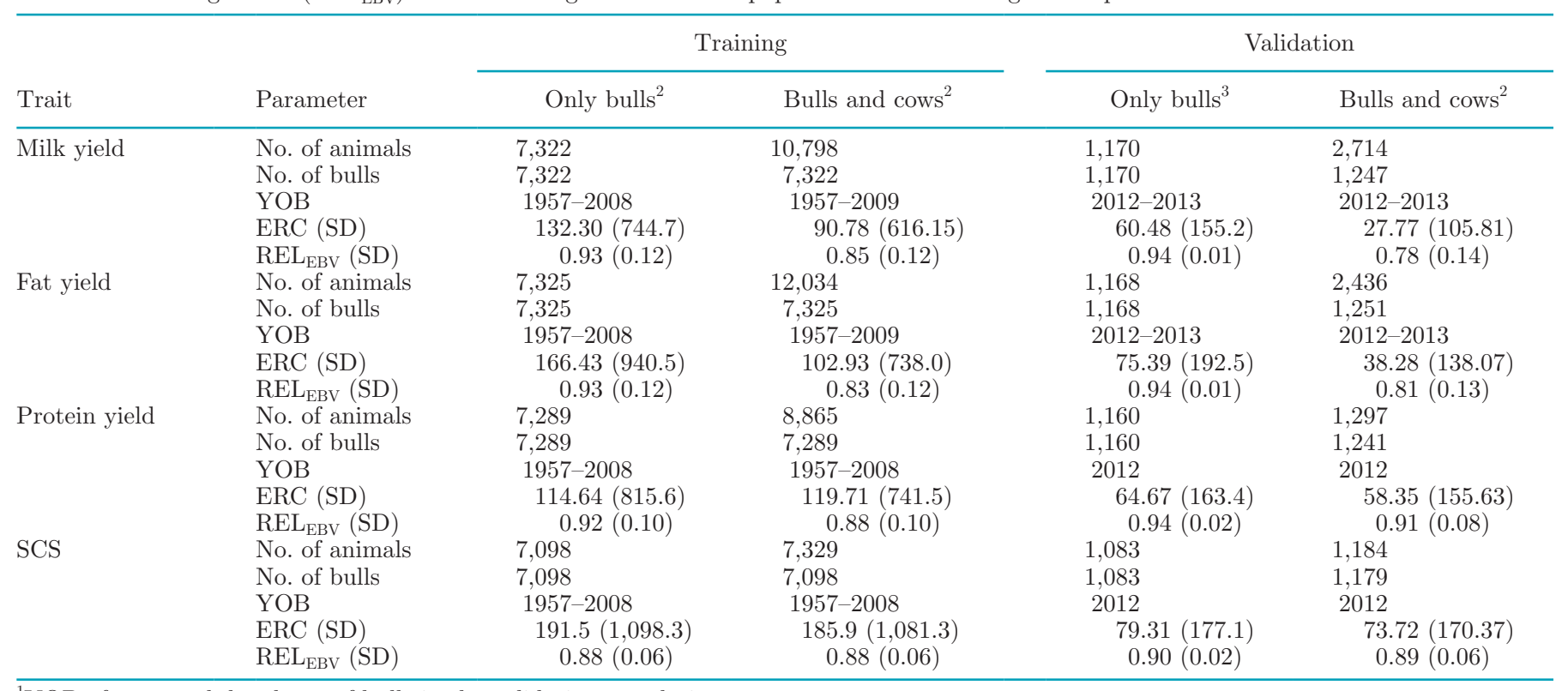

${ }^{1} \mathrm{YOB}$ of cows and daughters of bulls in the validation population.

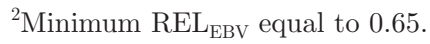

${ }^{3}$ Minimum REL $\mathrm{EBV}_{\mathrm{B}}$ equal to 0.80 . 
variance, $\mathbf{G}$ is the genomic relationship matrix, and $\mathbf{I}$ is the identity matrix. The vector of estimated DGV for all lactation days of animal $i$ and for each trait was obtained as follows:

$$
\mathbf{D G V}_{i}=\mathbf{T} \hat{\mathbf{g}}_{i}
$$

where $\hat{\mathbf{g}}_{i}$ is the vector of predicted genomic coefficients for each animal $i$, and $\mathbf{T}$ is a matrix of orthogonal covariates associated with the Legendre polynomial function. The AIREMLF90 software (Misztal et al., 2002) was used to obtain the variance components and the solutions of the mixed model equations (MME) for both P305 and RRM analyses.

GEBV and Theoretical Reliabilities. The GEBV of each animal $i$ for each DIM and for P305 were calculated by combining DGV with PA information using a selection index weighted by their theoretical reliabilities (Hayes et al., 2009):

$$
\mathrm{GEBV}_{i}=w_{1} \mathrm{PA}_{i}+w_{2} \mathrm{DGV}_{i}
$$

in which $w_{1}$ and $w_{2}$ were given by

$$
w_{1}=\frac{\mathrm{REL}_{\mathrm{PA}_{i}}}{\mathrm{REL}_{\mathrm{PA}_{i}}+\mathrm{REL}_{\mathrm{DGV}_{i}}}
$$

and

$$
w_{2}=\frac{\mathrm{REL}_{\mathrm{DGV}_{i}}}{\mathrm{REL}_{\mathrm{PA}_{i}}+\mathrm{REL}_{\mathrm{DGV}_{i}}},
$$

where $\mathrm{REL}_{\mathrm{DGV}}$ is the theoretical reliability of estimated $\mathrm{DGV}$. The $\mathrm{REL}_{\mathrm{DGV}}$ for each animal in the validation population was computed based on its prediction error variance (PEV). For the P305 analyses, the PEV matrix was estimated directly using the coefficient matrix extracted from the inverse of the left-hand side of the MME. Specifically for the RRM analyses, PEV for each animal $i$ and for each trait was estimated as in Mrode (2014):

$$
\mathbf{P E V}_{i}=\mathbf{T}^{\prime} \mathbf{C}^{\mathrm{ii}} \mathbf{T}
$$

where $\mathbf{T}$ is a matrix of orthogonal covariates associated with the Legendre polynomial function and $\mathbf{C}^{\mathrm{ii}}$ is the subset of the inverse of MME corresponding to the genomic effect for the animal $i$. Then, the $\mathrm{REL}_{\mathrm{DGV}_{i}}$ of animal $i$ for each DIM and for the P305 was computed as

$$
\mathrm{REL}_{\mathrm{DGV}_{i}}=1-\left(\frac{\mathrm{PEV}_{i}}{\sigma_{g}^{2}}\right),
$$

where $\sigma_{g}^{2}$ was the estimated genomic variance for each DIM or for P305.

The theoretical reliabilities of GEBV ( $\left.\mathrm{REL}_{\mathrm{GEBV}}\right)$ were approximated as

$$
\mathrm{REL}_{\mathrm{GEBV}_{i}}=w_{1} \mathrm{REL}_{\mathrm{PA}_{i}}+w_{2} \mathrm{REL}_{\mathrm{DGV}_{i}},
$$

where all terms were as defined previously. It is worth noting that the theoretical reliabilities of EBV initially made available by CDN for each animal and trait were average reliabilities for the first 3 lactations and that the same animals were included in the genomic analysis of all 3 lactations for a same trait (e.g., MY1, MY2, and MY3). Therefore, the same amount of information was available for each animal and trait. Thus, to avoid presenting redundant information, a single average theoretical reliability is reported for each trait, method, and scenario for both PA and GEBV.

GEBV Validation Reliability and Bias. To access the pattern of validation reliability and bias of GEBV over DIM, a proxy of the reliability of GEBV (validation reliability) obtained from the RRM for each trait was calculated as the squared Pearson correlation coefficient between GEBV (based on the 2012 genetic evaluation) and EBV (based on the 2016 genetic evaluation) for each DIM considering all individuals in the validation population. The validation reliabilities estimated in this study were not adjusted for the imperfect reliabilities of the 2016 EBV because only relatively accurate animals with similar reliability estimates were included in the validation population. In addition, regression coefficients $\left(b_{1}\right)$ were estimated using a linear regression of EBV on GEBV for each DIM (i.e., EBV $=b_{0}+b_{1} \times$ GEBV) to assess the prediction bias (inflation or deflation of the GEBV relative to EBV) over DIM.

Reliability and bias of PA and GEBV obtained from RRM were compared with those obtained from the traditional P305 models, which were estimated using EBV and GEBV for the accumulated yield. To facilitate the comparison between P305 and RRM, daily PA and daily GEBV obtained from the RRM were summed to generate accumulated PA and accumulated GEBV, respectively. Thereafter, validation reliability was estimated for PA and GEBV generated from both P305 and RRM using the squared Pearson correlation coefficient between accumulated PA and accumulated 
EBV and between accumulated GEBV and accumulated EBV, respectively. In addition, bias of PA and GEBV were estimated based on RRM and P305 models using a linear regression of accumulated EBV on accumulated PA $\left(b_{1}\right.$ obtained from accumulated EBV = $\mathrm{b}_{0}+\mathrm{b}_{1} \times$ accumulated PA) and of accumulated EBV on accumulated GEBV ( $b_{1}$ obtained from accumulated $\mathrm{EBV}=\mathrm{b}_{0}+\mathrm{b}_{1} \times$ accumulated GEBV), respectively.

\section{RESULTS}

\section{GEBV Theoretical Reliabilities}

Table 2 shows the average of theoretical reliabilities of PA and GEBV obtained based on P305 and RRM considering only bulls in the training and validation populations, bulls and cows in the training population and only bulls in the validation population, and bulls and cows in the training and validation populations. Theoretical reliabilities of GEBV obtained by the RRM were slightly greater than theoretical reliabilities obtained by the P305. For all traits, higher theoretical reliabilities were estimated for GEBV compared with PA. Theoretical reliabilities of PA and GEBV were higher for MY, FY, and PY compared with the ones observed for SCS.

In general, a slightly increase in theoretical reliabilities of GEBV was observed when including cows in the training population. However, similar theoretical reliabilities of GEBV were observed when including cows in the validation population. In addition, similar reliabilities were estimated for PA when including or not cows in both training and validation populations.

\section{GEBV Validation Reliability and Bias}

Table 3 shows the validation reliabilities estimated for PA and GEBV using P305 and RRM for all traits considering only bulls in the training and validation populations, bulls and cows in the training population and only bulls in the validation population, and bulls and cows in the training and validation populations. Similar validation reliabilities were estimated for PA using either P305 or RRM. However, reliabilities estimated for GEBV using P305 were generally higher than those estimated using RRM. Validation reliabilities estimated for GEBV were higher than validation reliabilities estimated for PA using both P305 and RRM. Higher validation reliabilities were estimated for PA and for GEBV when considering only bulls in the training and validation populations compared with the scenario in which cows were included using both P305 and RRM methods.

Table 4 shows the regression coefficients estimated using either P305 or RRM considering only bulls in the training and validation populations, bulls and cows in the training population and only bulls in the validation population, and bulls and cows in the training and validation populations. In general, regression coefficients closer to 1.0 were found using the RRM method for both PA and GEBV compared with using P305. The most biased estimates (regression coefficients deviating from 1.0) were observed for PA using the P305 method.

Overall, less biased GEBV were observed when considering only bulls in the training and validation populations compared with the scenario in which cows were also included in the training population. Similar

Table 2. Average (SD) of theoretical reliabilities of parent average $\left(\mathrm{REL}_{\mathrm{PA}}\right)$ and genomic estimated breeding value $\left(\mathrm{REL} \mathrm{GEBV}_{\mathrm{G}}\right)$ using the accumulated and random regression methods considering only bulls in the training and validation populations (bulls + bulls), bulls and cows in the training population and only bulls in the validation population (bulls and cows + bulls), and bulls and cows in the training and validation populations (bulls and cows + bulls and cows)

\begin{tabular}{|c|c|c|c|c|c|c|c|}
\hline Method & Trait $^{1}$ & \multicolumn{2}{|c|}{ Bulls + bulls } & \multicolumn{2}{|c|}{ Bulls and cows + bulls } & \multicolumn{2}{|c|}{ Bulls and cows + bulls and cows } \\
\hline \multirow[t]{3}{*}{ Accumulated } & MY & $0.40(0.047)$ & $0.72(0.011)$ & $0.40(0.047)$ & $0.75(0.013)$ & $0.40(0.043)$ & $0.75(0.011)$ \\
\hline & PY & $0.40(0.047)$ & $0.72(0.011)$ & $0.40(0.047)$ & $0.73(0.014)$ & $0.40(0.048)$ & $0.73(0.011)$ \\
\hline & SCS & $0.37(0.047)$ & $0.71(0.011)$ & $0.37(0.047)$ & $0.71(0.013)$ & $0.37(0.049)$ & $0.71(0.011)$ \\
\hline Mean & & 0.40 & 0.72 & 0.40 & 0.74 & 0.40 & 0.74 \\
\hline \multirow{3}{*}{ Regression } & FY & $0.41(0.049)$ & $0.73(0.011)$ & $0.40(0.049)$ & $0.76(0.049)$ & $0.40(0.049)$ & $0.76(0.011)$ \\
\hline & PY & $0.40(0.048)$ & $0.73(0.011)$ & $0.40(0.048)$ & $0.75(0.013)$ & $0.40(0.048)$ & $0.75(0.013)$ \\
\hline & SCS & $0.37(0.049)$ & $0.72(0.010)$ & $0.37(0.049)$ & $0.73(0.013)$ & $0.37(0.049)$ & $0.73(0.013)$ \\
\hline Mean & & 0.39 & 0.73 & 0.39 & 0.75 & 0.39 & 0.75 \\
\hline
\end{tabular}

${ }^{1} \mathrm{MY}=$ milk yield; $\mathrm{FY}=$ fat yield; $\mathrm{PY}=$ protein yield. 
regression coefficients were estimated when including or not cows in the validation population.

\section{Validation Reliability and Bias of GEBV over DIM}

Validation reliability and bias pattern of GEBV over DIM for each trait, estimated using only bulls in the training and validation populations, are shown in Figure 1. In summary, different validation reliability and bias patterns for the GEBV along the lactation curve were observed for different traits and lactations.

\section{DISCUSSION}

\section{GEBV Theoretical Reliabilities}

Theoretical reliabilities are related to the amount of information available in the MME. Therefore, the use of RRM to estimate daily DGV (and consequently daily GEBV) increased the amount of information available in the MME, which yielded a slight increase in theoretical reliabilities of GEBV obtained from the RRM when compared with P305. For both RRM and P305, including genomic information in the estimation of breeding values increased the theoretical reliabilities for all traits (Table 2), which is in agreement with other studies (e.g., VanRaden et al., 2009; Ding et al., 2013).

In general, theoretical reliabilities estimated in this study were high (greater than 0.37 for PA and 0.71 for GEBV). This is related to the reduction in the PEV due to the use of deregressed EBV as pseudophenotypes (compared with the use of actual phenotypes) and to the high reliability threshold used to select animals included in the training and validation populations. Lower theoretical reliabilities were obtained for SCS due to the lower heritability and the smaller number

Table 3. Validation reliabilities estimated for parent average $\left(r_{\mathrm{PA}}^{2}\right)$ and for genomic estimated breeding value $\left(r_{\mathrm{GEBV}}^{2}\right)$ using the accumulated and random regression methods considering only bulls in the training and validation populations (bulls + bulls), bulls and cows in the training population and only bulls in the validation population (bulls and cows + bulls), and bulls and cows in the training and validation populations (bulls and cows + bulls and cows)

\begin{tabular}{|c|c|c|c|c|c|c|c|}
\hline \multirow[b]{2}{*}{ Method } & \multirow[b]{2}{*}{ Trait $^{1}$} & \multicolumn{2}{|c|}{ Bulls + bulls } & \multicolumn{2}{|c|}{ Bulls and cows + bulls } & \multicolumn{2}{|c|}{ Bulls and cows + bulls and cows } \\
\hline & & $r_{\mathrm{PA}}^{2}$ & $r_{\mathrm{GEBV}}^{2}$ & $r_{\mathrm{PA}}^{2}$ & $r_{\mathrm{GEBV}}^{2}$ & $r_{\mathrm{PA}}^{2}$ & $r_{\mathrm{GEBV}}^{2}$ \\
\hline \multirow[t]{12}{*}{ Accumulated } & MY1 & 0.43 & 0.55 & 0.42 & 0.52 & 0.35 & 0.47 \\
\hline & MY2 & 0.41 & 0.49 & 0.40 & 0.48 & 0.34 & 0.44 \\
\hline & MY3 & 0.40 & 0.50 & 0.40 & 0.49 & 0.37 & 0.46 \\
\hline & FY1 & 0.40 & 0.55 & 0.40 & 0.50 & 0.36 & 0.45 \\
\hline & FY2 & 0.39 & 0.53 & 0.38 & 0.50 & 0.37 & 0.44 \\
\hline & FY3 & 0.41 & 0.56 & 0.40 & 0.53 & 0.40 & 0.46 \\
\hline & PY1 & 0.41 & 0.52 & 0.41 & 0.45 & 0.40 & 0.44 \\
\hline & PY2 & 0.44 & 0.52 & 0.42 & 0.44 & 0.43 & 0.42 \\
\hline & $\mathrm{PY} 3$ & 0.46 & 0.53 & 0.45 & 0.48 & 0.47 & 0.47 \\
\hline & SCS1 & 0.31 & 0.42 & 0.31 & 0.42 & 0.32 & 0.38 \\
\hline & SCS2 & 0.37 & 0.44 & 0.37 & 0.45 & 0.37 & 0.41 \\
\hline & SCS3 & 0.38 & 0.44 & 0.38 & 0.44 & 0.39 & 0.38 \\
\hline Mean & & 0.40 & 0.50 & 0.40 & 0.48 & 0.38 & 0.45 \\
\hline \multirow[t]{12}{*}{ Regression } & MY1 & 0.42 & 0.54 & 0.42 & 0.48 & 0.36 & 0.48 \\
\hline & MY2 & 0.40 & 0.49 & 0.39 & 0.44 & 0.34 & 0.44 \\
\hline & MY3 & 0.40 & 0.50 & 0.40 & 0.46 & 0.37 & 0.44 \\
\hline & FY1 & 0.41 & 0.52 & 0.40 & 0.44 & 0.36 & 0.45 \\
\hline & $\mathrm{FY} 2$ & 0.37 & 0.52 & 0.38 & 0.47 & 0.37 & 0.45 \\
\hline & FY3 & 0.40 & 0.55 & 0.39 & 0.50 & 0.40 & 0.47 \\
\hline & PY1 & 0.41 & 0.51 & 0.42 & 0.42 & 0.40 & 0.43 \\
\hline & PY2 & 0.43 & 0.50 & 0.44 & 0.41 & 0.43 & 0.42 \\
\hline & PY3 & 0.46 & 0.53 & 0.47 & 0.46 & 0.46 & 0.46 \\
\hline & SCS1 & 0.30 & 0.40 & 0.31 & 0.40 & 0.31 & 0.40 \\
\hline & SCS2 & 0.35 & 0.41 & 0.37 & 0.41 & 0.37 & 0.41 \\
\hline & SCS3 & 0.38 & 0.40 & 0.38 & 0.38 & 0.38 & 0.41 \\
\hline Mean & & 0.39 & 0.49 & 0.40 & 0.44 & 0.38 & 0.44 \\
\hline
\end{tabular}

${ }^{1}$ Milk (MY1, MY2, MY3), fat (FY1, FY2, FY3), and protein (PY1, PY2, PY3) yields and SCS (SCS1, SCS2, SCS3) in the first, second, and third lactations, respectively. 
Table 4. Regression coefficients $\pm \mathrm{SE}$ estimated for parent average $\left(\mathrm{b}_{\mathrm{PA}}\right)$ and for genomic estimated breeding value $\left(\mathrm{b}_{\mathrm{GEBV}}\right)$ using the accumulated and random regression methods considering only bulls in the training and validation populations (bulls + bulls), bulls and cows in the training population and only bulls in the validation population (bulls and cows + bulls), and bulls and cows in the training and validation populations (bulls and cows + bulls and cows)

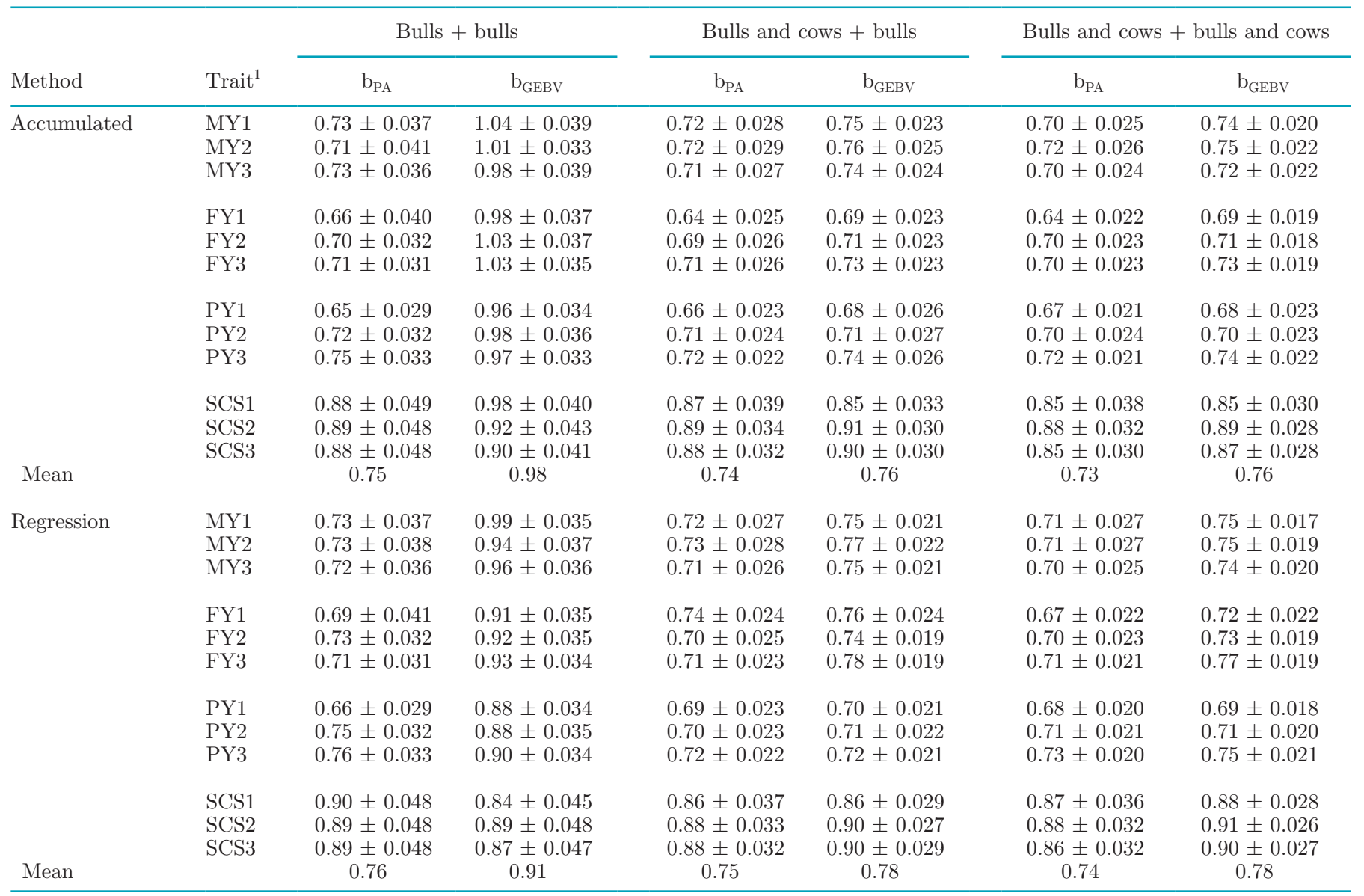

${ }^{1}$ Milk (MY1, MY2, MY3), fat (FY1, FY2, FY3), and protein (PY1, PY2, PY3) yields and SCS (SCS1, SCS2, SCS3) in the first, second, and third lactations, respectively.

of animals in the $\mathbf{G}$ matrix for this trait when compared with the other traits, which consequently reflects a smaller amount of information. The reason for the smaller number of genotyped animals in the $\mathbf{G}$ matrix for SCS is the threshold for minimum reliability used to define the training and validation populations.

\section{GEBV Validation Reliability and Bias}

Similar validation reliabilities estimated for PA were obtained using P305 and RRM (Table 3) because the accumulated PA and EBV were estimated based on daily PA and EBV, which makes them more highly correlated. Using RRM, the validation reliabilities of GEBV for almost all traits were lower compared with P305 models. This may be expected because it is more difficult to predict GEBV for each DIM, resulting in larger total amount of estimation error when compared with the use of P305. In general, the inclusion of genomic information increased the validation reliability for almost all traits because GEBV take also into account the Mendelian sampling term and, therefore, they are a more useful estimate of the genetic merit of young animals for the lactation pattern compared with the PA. Validation reliabilities for GEBV estimated in this study were similar to those reported in a study using single-step GBLUP methodology and a multiplelactation random regression test-day model for genomic predictions in Japanese Holstein cattle (Baba et al., 2017).

Linear regression coefficients of EBV on GEBV lower than 1.0 may indicate overestimation of the GEBV. Regression coefficients closer to 1.0 were found using RRM (Table 4), likely because currently selection based on the pattern of the lactation curve in dairy cattle has been based solely on lactation persistency 
a

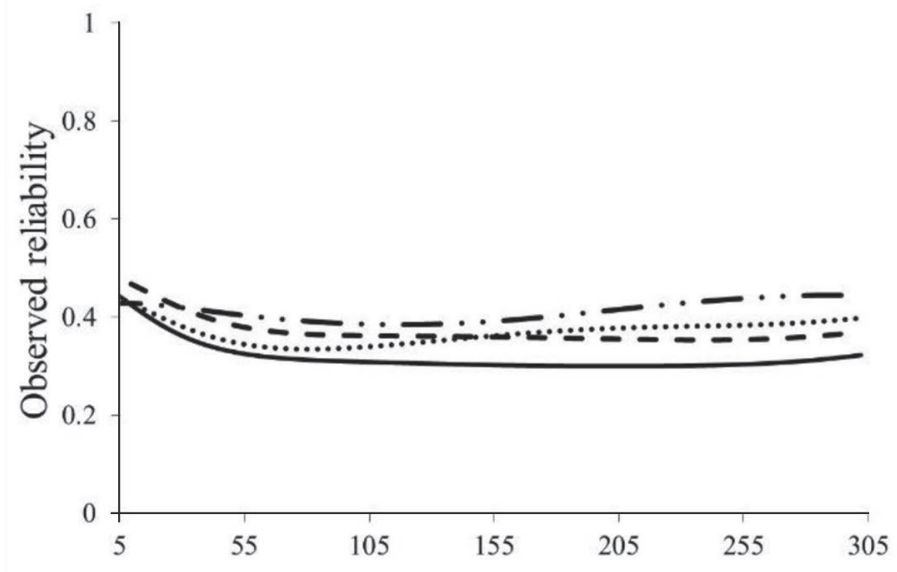

b

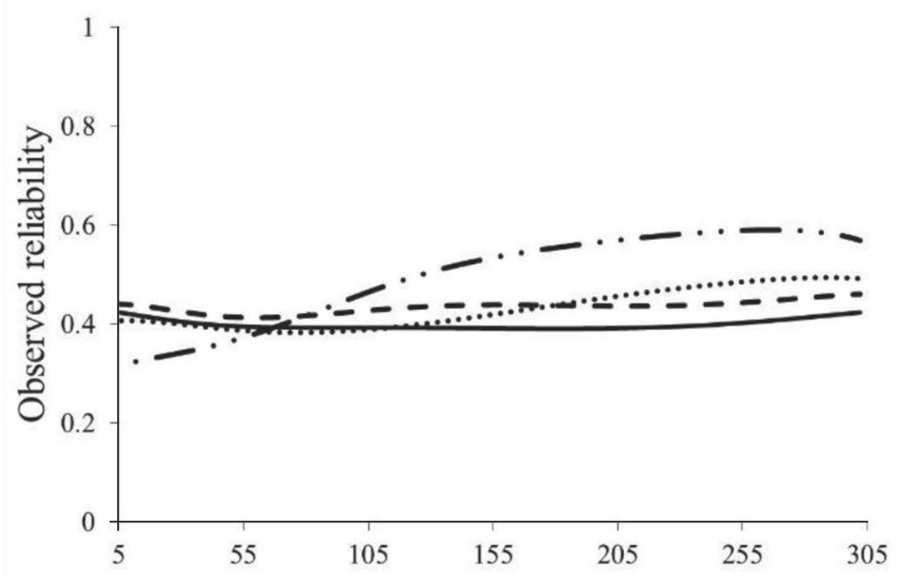

c

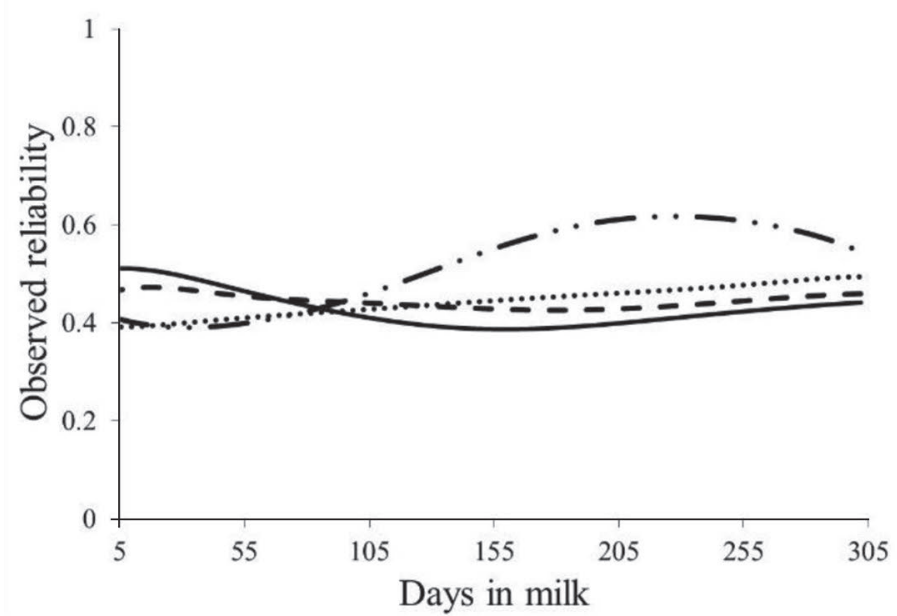

d

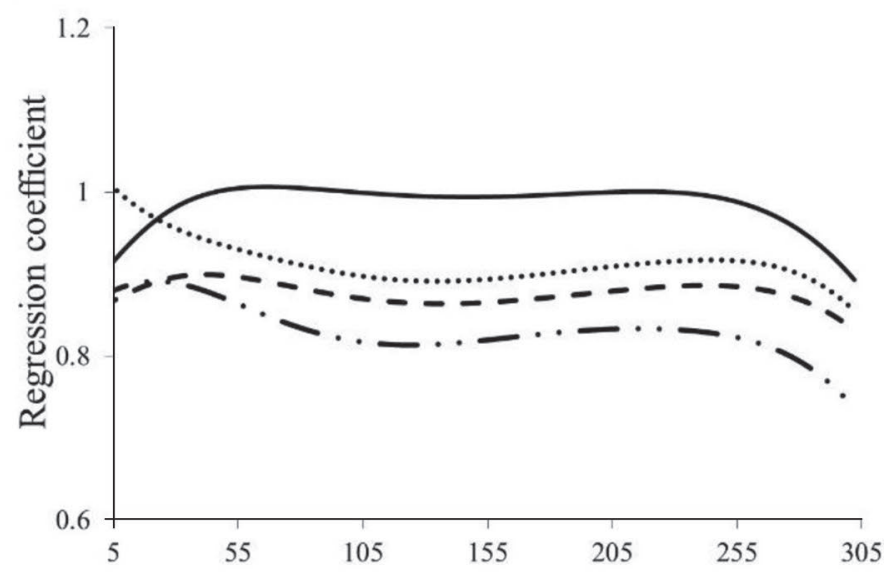

e

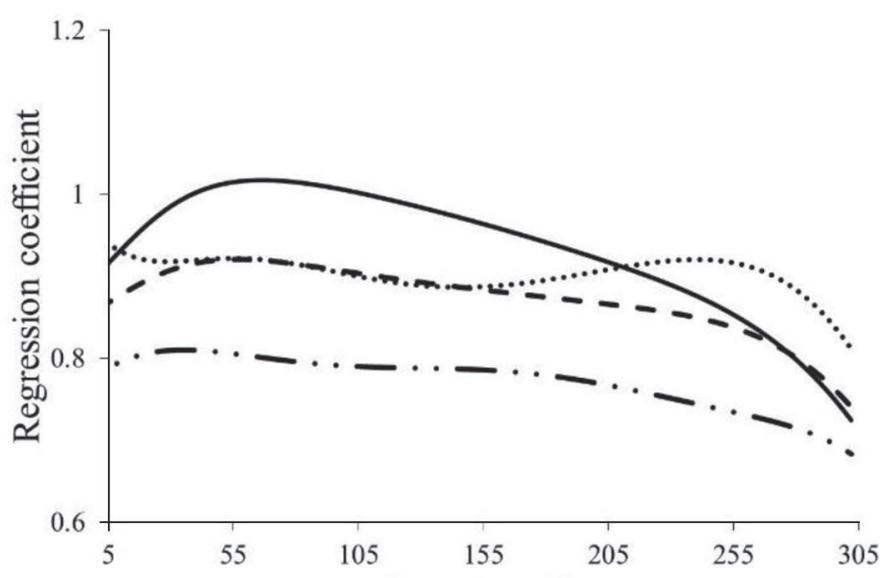

f

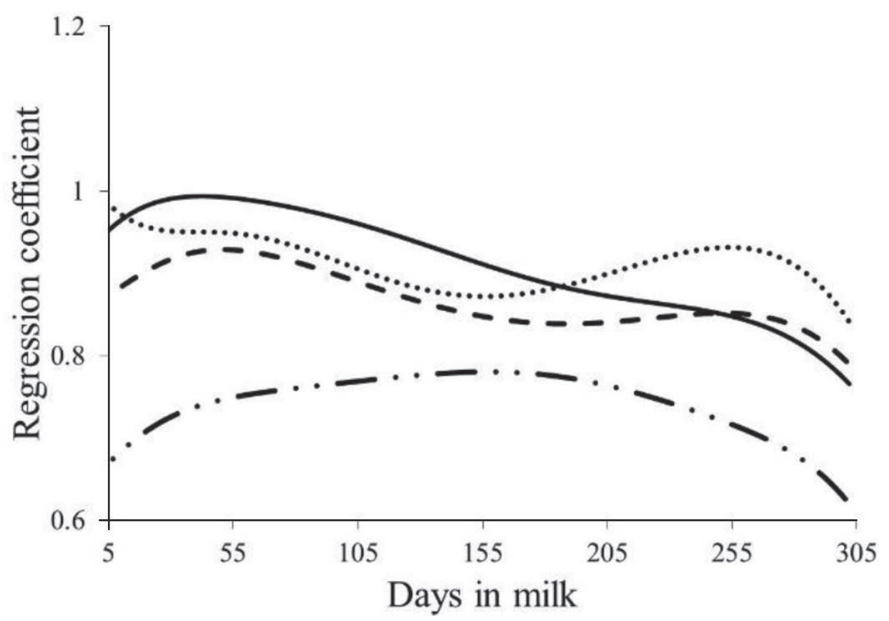

Figure 1. Validation reliability (a, b, c) and bias (regression coefficients; d, e, f) patterns of genomic EBV over DIM for milk (solid line), fat (dotted line), and protein (dashed line) yields and SCS (dashed-dotted line) from the first (a, d), second (b, e), and third (c, f) lactations. 
measurements, a more recent criterion than other milk production traits (e.g., accumulated yield). Regression coefficients of GEBV estimated in this study were not compared with other studies using RRM because they have used the single-step GBLUP approach and alternative scaling factors to combine the genomic $(\mathbf{G})$ and pedigree-based additive (A) relationship matrices (Koivula et al., 2015; Baba et al., 2017). Scaling factors used to adjust the $\mathbf{G}$ matrix toward their expected values in the $\mathbf{A}$ matrix have been shown to have a high impact on bias in single-step genomic evaluations (Vitezica et al., 2011; Christensen et al., 2012; Koivula et al., 2015).

\section{Validation Reliability and Bias of GEBV over DIM}

Using the complete lactation curve to genetically select animals has been a complex task over past decades. To simplify the genetic evaluation process in breeding programs around the world, the feasibility of selecting for specific lactation curve patterns or traits derived from it, such as lactation persistence and lactation peak, has been investigated. In addition, there is great interest from the industry on deriving additional traits based on the lactation pattern and, for instance, its association with metabolic diseases (Miglior et al., 2017). Our study shows that genomics is a feasible alternative for accurately predicting the lactation pattern of Holstein animals at an early age (without own phenotypes or progeny information), which would be useful when evaluating traits associated with the lactation pattern. The different validation reliability and bias patterns for the GEBV along the lactation curve, for different traits and lactations, suggest that selection based on different lactation periods may have different usefulness (Figure 1). Furthermore, it implies that different genes might be expressed over DIM and, consequently, that selection based on different lactation periods may have distinct genetic consequences on the lactation curve. Thus, this study indicates the need to re-evaluate statistical methods that have been used for selecting for lactation pattern (e.g., lactation persistency) because they were developed before the wide availability and use of genomic information (e.g., Rowlands et al., 1982; Cole and Null, 2009). The investigation of appropriate parameters to better summarize the lactation curve pattern when including genomic information may increase genetic progress for production traits while contributing to improve health, welfare, and fertility traits in dairy cattle. In addition, genome-wide association studies (GWAS) considering the whole lactation curve may help to better understand the genetic background of the biology of the lactation curve. Comparisons of results found here with those from other studies were not possible because the studies found in the literature based on RRM have not reported reliabilities and bias over DIM (Koivula et al., 2015; Jattawa et al., 2016; Baba et al., 2017).

\section{Effect of Incorporating Cows in the Training and Validation Populations}

The inclusion of cows in the training population yielded a slight increase in the theoretical reliabilities of GEBV (Table 2), which may be related to the increase in the amount of information available for the analyses. These findings are in agreement with previous studies that also showed that adding cows in the training population may significantly improve the theoretical reliabilities (Gao et al., 2015; Su et al., 2016). Although several studies have evaluated the effect of including cows in the training population of different dairy cattle breeds (e.g., Gao et al., 2015; Koivula et al., 2016; Su et al., 2016), to our best knowledge no studies have evaluated the effect of including cows in the validation population, especially under an RRM approach. Similar theoretical reliabilities were observed for GEBV when including cows in the validation population using both the P305 and RRM methods. In addition, similar theoretical reliabilities of PA were estimated when including or not cows in the training and validation populations.

A slight increase in the validation reliabilities was observed when including only bulls in the training and validation populations compared with the inclusion of both bulls and cows in the training population (Table $3)$. This may be related to the less reliable deregressed EBV from cows compared with bulls (Uemoto et al., 2017). Reliable deregressed EBV in the training population are required to accurately estimate the marker effects (and GEBV), whereas reliable information in the validation population is required to validate the GEBV properly. In general, about 10 additional cows are required to yield the same amount of information provided by a single progeny-tested bull (Weller, 2016). Nowadays, official genomic evaluations for the Holstein breed in Canada only include bulls in the training and validation populations (Interbull, 2017). In addition, various studies have included only bulls in the validation population (e.g., Gao et al., 2015; Koivula et al., 2015; Baba et al., 2017).

The inclusion of cows in the training population made the regression coefficients for the GEBV lower than 1.0 and more similar to the regression coefficients observed for the PA compared with when only bulls were included in the training population, in which the coefficients were all close to 1.0 (Table 4). This may be related to the difference of EBV scale between cows and bulls, which can be caused, for instance, by cow 
preferential treatment (Wiggans et al., 2011). To solve this scaling problem, official evaluations in the United States consider some adjustment factors (Wiggans et al., 2011). No ad hoc adjustments were used in our study. The inclusion of cows in the validation population did not seem to affect the regression coefficients estimated for PA and GEBV (Table 4).

\section{CONCLUSIONS}

Validation reliability of RRM GEBV was in general lower than the validation reliability for the P305 model. Nevertheless, overall RRM provided less biased GEBV compared with the P305 model. More important, the use of RRM in 2-step GWS produced fairly accurate GEBV over the entire lactation curve for milk, fat, and protein yields and SCS. Thus, selecting young animals based on the pattern of genomically predicted lactation curves seems feasible in Holstein cattle.

\section{ACKNOWLEDGMENTS}

The authors gratefully acknowledge the financial support of this research from Agriculture and AgriFood Canada (Guelph, ON, Canada) and additional contributions from Dairy Farmers of Canada (Ottawa, ON, Canada), the Canadian Dairy Network (Guelph, ON, Canada), and the Canadian Dairy Commission (Ottawa, ON, Canada) under the Agri-Science Clusters Initiative.

\section{REFERENCES}

Aguilar, I., I. Misztal, D. Johnson, A. Legarra, S. Tsuruta, and T. Lawlor. 2010. Hot topic: A unified approach to utilize phenotypic, full pedigree, and genomic information for genetic evaluation of Holstein final score. J. Dairy Sci. 93:743-752. https://doi.org/10 $.3168 /$ jds.2009-2730.

Aguilar, I., I. Misztal, S. Tsuruta, A. Legarra, and H. Wang. 2014. PREGSF90-POSTGSF90: Computational tools for the implementation of single-step genomic selection and genome-wide association with ungenotyped individuals in BLUPF90 programs. Pages 1-3 in Proc. 10th World Congr. Genet. Appl. Livest. Prod., Vancouver, BC, Canada. Am. Soc. Anim. Sci., Champaign, IL. https: //doi.org/10.13140/2.1.4801.5045.

Aliloo, H., J. E. Pryce, O. González-Recio, B. G. Cocks, and B. J. Hayes. 2016. Accounting for dominance to improve genomic evaluations of dairy cows for fertility and milk production traits. Genet. Sel. Evol. 48:8. https://doi.org/10.1186/s12711-016-0186-0.

Baba, T., Y. Gotoh, S. Yamaguchi, S. Nakagawa, H. Abe, Y. Masuda, and T. Kawahara. 2017. Application of single-step genomic best linear unbiased prediction with a multiple-lactation random regression test-day model for Japanese Holsteins. Anim. Sci. J. 88:1226-1231. https://doi.org/10.1111/asj.12760.

Brown, A., J. Ojango, J. Gibson, M. Coffey, M. Okeyo, and R. Mrode. 2016. Short communication: Genomic selection in a crossbred cattle population using data from the Dairy Genetics East Africa Project. J. Dairy Sci. 99:7308-7312. https://doi.org/10.3168/jds .2016-11083.
Christensen, O. F., and M. S. Lund. 2010. Genomic prediction when some animals are not genotyped. Genet. Sel. Evol. 42:2. https:// doi.org/10.1186/1297-9686-42-2.

Christensen, O. F., P. Madsen, B. Nielsen, T. Ostersen, and G. Su. 2012. Single-step methods for genomic evaluation in pigs. Animal 6:1565-1571. https://doi.org/10.1017/S1751731112000742.

Cole, J. B., and D. J. Null. 2009. Genetic evaluation of lactation persistency for five breeds of dairy cattle. J. Dairy Sci. 92:2248-2258. https://doi.org/10.3168/jds.2008-1825.

Ding, X., Z. Zhang, X. Li, S. Wang, X. Wu, D. Sun, Y. Yu, J. Liu, Y. Wang, and Y. Zhang. 2013. Accuracy of genomic prediction for milk production traits in the Chinese Holstein population using a reference population consisting of cows. J. Dairy Sci. 96:53155323. https://doi.org/10.3168/jds.2012-6194.

Gao, H., P. Madsen, U. Nielsen, G. Aamand, G. Su, K. Byskov, and J. Jensen. 2015. Including different groups of genotyped females for genomic prediction in a Nordic Jersey population. J. Dairy Sci. 98:9051-9059. https://doi.org/10.3168/jds.2015-9947.

Garrick, D. J., J. F. Taylor, and R. L. Fernando. 2009. Deregressing estimated breeding values and weighting information for genomic regression analyses. Genet. Sel. Evol. 41:55. https://doi.org/10 $.1186 / 1297-9686-41-55$.

Hayes, B. J., P. J. Bowman, A. Chamberlain, and M. Goddard. 2009. Invited review: Genomic selection in dairy cattle: Progress and challenges. J. Dairy Sci. 92:433-443. https://doi.org/10.3168/jds .2008-1646.

Interbull. 2017. Description of national genomic evaluation systems. Accessed May 2, 2018. http://www.interbull.org/ib/ nationalgenoforms.

Interbull. 2018a. Description of national genetic evaluation system and trend validation for production traits. Accessed May 2, 2018. http: //www.interbull.org/ib/geforms.

Interbull. 2018b. Description of national genetic evaluation system and trend validation for milk somatic cell and clinical mastitis. Accessed May 2, 2018. http://www.interbull.org/ib/geforms.

Jattawa, D., M. A. Elzo, S. Koonawootrittriron, and T. Suwanasopee. 2016. Genomic-polygenic and polygenic evaluations for milk yield and fat percentage using random regression models with Legendre polynomials in a Thai multibreed dairy population. Livest. Sci. 188:133-141. https://doi.org/10.1016/j.livsci.2016.04.019.

Jenko, J., G. Wiggans, T. Cooper, S. Eaglen, W. L. Luff, M. Bichard, R. Pong-Wong, and J. Woolliams. 2017. Cow genotyping strategies for genomic selection in a small dairy cattle population. J. Dairy Sci. 100:439-452. https://doi.org/10.3168/jds.2016-11479.

Jensen, J. 2001. Genetic evaluation of dairy cattle using test-day models. J. Dairy Sci. 84:2803-2812. https://doi.org/10.3168/jds.S0022 -0302(01)74736-4.

Kirkpatrick, M., D. Lofsvold, and M. Bulmer. 1990. Analysis of the inheritance, selection and evolution of growth trajectories. Genetics 124:979-993.

Koivula, M., I. Strandén, G. P. Aamand, and E. A. Mäntysaari. 2016. Effect of cow reference group on validation reliability of genomic evaluation. Animal 10:1061-1066. https://doi.org/10.1017/ S1751731115002864.

Koivula, M., I. Strandén, J. Pösö, G. Aamand, and E. Mäntysaari. 2015. Single-step genomic evaluation using multitrait random regression model and test-day data. J. Dairy Sci. 98:2775-2784. https://doi.org/10.3168/jds.2014-8975.

Larmer, S. G., M. Sargolzaei, and F. Schenkel. 2014. Extent of linkage disequilibrium, consistency of gametic phase, and imputation accuracy within and across Canadian dairy breeds. J. Dairy Sci. 97:3128-3141. https://doi.org/10.3168/jds.2013-6826.

Miglior, F., A. Fleming, F. Malchiodi, L. F. Brito, P. Martin, and C. F. Baes. 2017. A 100-year review: Identification and genetic selection of economically important traits in dairy cattle. J. Dairy Sci. 100:10251-10271. https://doi.org/10.3168/jds.2017-12968.

Misztal, I., A. Legarra, and I. Aguilar. 2009. Computing procedures for genetic evaluation including phenotypic, full pedigree, and genomic information. J. Dairy Sci. 92:4648-4655. https://doi.org/10 $.3168 /$ jds.2009-2064. 
Misztal, I., S. Tsuruta, T. Strabel, B. Auvray, T. Druet, and D. Lee. 2002. BLUPF90 and related programs (BGF90). Pages 21-22 in Proc. 7th World Congr. Genet. Appl. Livest. Prod., Montpellier, France. Editions Quae, Montpellier, France.

Mrode, R. A. 2014. Linear Models for the Prediction of Animal Breeding Values. 3rd ed. CAB International, Wallingford, UK.

Oliveira, H. R., F. F. Silva, L. F. Brito, A. R. Guarini, J. Jamrozik, and F. S. Schenkel. 2018. Comparing deregression methods for genomic prediction of test-day traits in dairy cattle. J. Anim. Breed. Genet. 135:97-106. https://doi.org/10.1111/jbg.12317.

Přibyl, J., P. Madsen, J. Bauer, J. Přibylová, M. Šimečková, L. Vostrý, and L. Zavadilová. 2013. Contribution of domestic production records, Interbull estimated breeding values, and single nucleotide polymorphism genetic markers to the single-step genomic evaluation of milk production. J. Dairy Sci. 96:1865-1873. https://doi .org/10.3168/jds.2012-6157.

Rowlands, G., S. Lucey, and A. Russell. 1982. A comparison of different models of the lactation curve in dairy cattle. Anim. Sci. 35:135-144. https://doi.org/10.1017/S0003356100000908.

Sargolzaei, M., J. P. Chesnais, and F. S. Schenkel. 2011. FImputeAn efficient imputation algorithm for dairy cattle populations. J. Dairy Sci. 94(E-Suppl. 1):421. (Abstr.)

Schaeffer, L. R. 2006. Strategy for applying genome-wide selection in dairy cattle. J. Anim. Breed. Genet. 123:218-223. https://doi.org/ 10.1111/j.1439-0388.2006.00595.x.

Schaeffer, L. R., J. Jamrozik, G. Kistemaker, and J. Van Doormaal. 2000. Experience with a test-day model. J. Dairy Sci. 83:11351144. https://doi.org/10.3168/jds.S0022-0302(00)74979-4.

Su, G., P. Ma, U. S. Nielsen, G. P. Aamand, G. Wiggans, B. Guldbrandtsen, and M. Lund. 2016. Sharing reference data and including cows in the reference population improve genomic predictions in Danish Jersey. Animal 10:1067-1075. https://doi.org/10.1017/ S1751731115001792.
Uemoto, Y., T. Osawa, and J. Saburi. 2017. Effect of genotyped cows in the reference population on the genomic evaluation of Holstein cattle. Animal 11:382-393. https://doi.org/10.1017/ S1751731116001762.

VanRaden, P. M., C. Van Tassell, G. Wiggans, T. Sonstegard, R. Schnabel, J. Taylor, and F. Schenkel. 2009. Invited review: Reliability of genomic predictions for North American Holstein bulls. J. Dairy Sci. 92:16-24. https://doi.org/10.3168/jds.2008-1514.

VanRaden, P. M., and G. Wiggans. 1991. Derivation, calculation, and use of national animal model information. J. Dairy Sci. 74:27372746. https://doi.org/10.3168/jds.S0022-0302(91)78453-1.

VanRaden, P. M. 2008. Efficient methods to compute genomic predictions. J. Dairy Sci. 91:4414-4423. https://doi.org/10.3168/jds 2007-0980.

Vitezica, Z. G., I. Aguilar, I. Misztal, and A. Legarra. 2011. Bias in genomic predictions for populations under selection. Genet. Res. (Camb.) 93:357-366. https://doi.org/10.1017/ S001667231100022X.

Weller, J. I. 2016. Genomic Selection in Animals. Wiley, Hoboken, NJ.

Wiggans, G. R., T. Cooper, P. VanRaden, and J. Cole. 2011. Technical note: Adjustment of traditional cow evaluations to improve accuracy of genomic predictions. J. Dairy Sci. 94:6188-6193. https:// doi.org/10.3168/jds.2011-4481.

Wiggans, G. R., T. Sonstegard, P. VanRaden, L. Matukumalli, R. Schnabel, J. Taylor, F. Schenkel, and C. Van Tassell. 2009. Selection of single-nucleotide polymorphisms and quality of genotypes used in genomic evaluation of dairy cattle in the United States and Canada. J. Dairy Sci. 92:3431-3436. https://doi.org/10.3168/ jds.2008-1758.

Winkelman, A. M., D. Johnson, and B. Harris. 2015. Application of genomic evaluation to dairy cattle in New Zealand. J. Dairy Sci. 98:659-675. https://doi.org/10.3168/jds.2014-8560. 